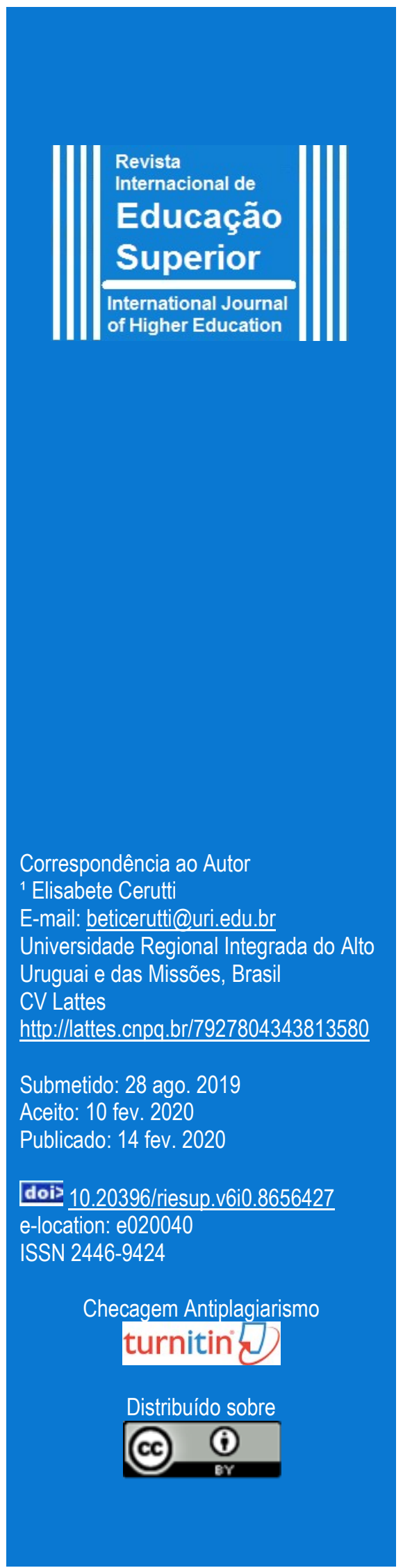

\title{
Tecendo Saberes Sobre as Tecnologias Assistivas Para o Sujeito Surdo no Ensino Superior
}

\section{Elisabete Cerutti ${ }^{1}{ }^{10}$ https://orcid.org/0000-0002-3467-5052}

${ }^{1}$ Universidade Regional Integrada do Alto Uruguai e das Missões

\section{RESUMO}

Refletir sobre a educação dos sujeitos surdos no Ensino Superior, reportanos a encontrar possibilidades junto ao uso das tecnologias assistivas. Esta pesquisa, de cunho bibliográfico, busca analisar como vem sendo regulamentada a acessibilidade do sujeito surdo através de tecnologia assistiva no Ensino Superior e quais dessas regulamentações podem diminuir as barreiras comunicacionais entre ouvintes e surdos. Traz as principais considerações em uma reflexão sobre a comunidade surda, buscando amparos teóricos para caracterizá-la. Também, abordamos a evolução das tecnologias, realizando uma reflexão sobre a inserção das mesmas no cotidiano, bem como, as principais regulamentações que amparam o cuidado com o sujeito surdo. Ainda, pesquisamos sobre como no campo teórico vem sendo discutida a inclusão dos sujeitos surdos no Ensino Superior e como as IES podem diminuir as barreiras comunicacionais entre os sujeitos ouvintes e os sujeitos surdos. Concluímos que as tecnologias assistivas são instrumentos capazes de facilitar a comunicação entre os sujeitos e que, para haver a inclusão dos sujeitos surdos, precisamos romper as barreiras físicas, metodológicas e atitudinais, visando uma constituir que as IES construam um desenho universal na qual todos se sintam cidadãos com os mesmos direitos para expressarem-se e terem acesso à construção do conhecimento profissional e pessoal

\section{PALAVRAS-CHAVE}

Ensino superior. Tecnologia assistiva. Sujeito surdo. Regulação.

Universidade Regional Integrada do Alto

CV Lattes

htio://lattes cnog br/7927804343813580

Submetido: 28 ago. 2019

Aceito: 10 fev. 2020

Publicado: 14 fev. 2020

\section{dois 10.20396/riesup.v6i0.8656427} e-location: e020040

ISSN 2446-9424

hecagem Antiplagiarismo

Distribuído sobre 


\title{
Weaving Knowledge About Assistive Technologies for the Deaf Subject in Higher Education
}

\begin{abstract}
Reflecting on the education of deaf subjects in Higher Education, tells us to find possibilities with the use of assistive technologies. This bibliographic research seeks to analyze how the accessibility of the deaf subject has been regulated through Assistive Technology in Higher Education and which of these can reduce the communication barriers between deaf and hearing. It brings the main considerations in a reflection on the deaf community, seeking theoretical supports to characterize it. Also, we approach the evolution of technologies, making a reflection on their insertion in daily life, as well as the main regulations that support the care of the deaf subject and research on how the inclusion of deaf subjects in Teaching has been discussed. Higher Education and how HEIs can reduce the communication barriers between hearing subjects and deaf subjects. We conclude that assistive technologies are instruments capable of facilitating communication between the subjects and that, in order to include deaf subjects, we need to break through the physical, methodological and attitudinal barriers, aiming at constituting that the HEIs build a universal design in which everyone feel citizens with the same rights to express themselves and have access to the construction of professional and personal knowledge.
\end{abstract}

\section{KEYWORDS}

University education. Assistive technology. Deaf subject. Regulation.

\section{Tejiendo Conocimiento Sobre Tecnologías de Asistencia Para Sordos en la Educación Superior}

\section{RESUMEN}

Reflexionando sobre la educación de las personas sordas en la Educación Superior, nos dice que encontremos posibilidades con el uso de tecnologías de asistencia. Esta investigación bibliográfica busca analizar cómo se ha regulado la accesibilidad del sujeto sordo a través de la tecnología de asistencia en la educación superior y cuáles de estos pueden reducir las barreras de comunicación entre sordos y oyentes. Trae las principales consideraciones en una reflexión sobre la comunidad sorda, buscando apoyos teóricos para caracterizarla. Además, nos acercamos a la evolución de las tecnologías, reflexionando sobre su inserción en la vida cotidiana, así como las principales regulaciones que apoyan el cuidado de las personas sordas y la investigación sobre cómo se ha discutido la inclusión de las personas sordas en la enseñanza. Educación superior y cómo las IES pueden reducir las barreras de comunicación entre los sujetos con audición y los sordos. Concluimos que las tecnologías de asistencia son instrumentos capaces de facilitar la comunicación entre los sujetos y que, para incluir a los sordos, necesitamos romper las barreras físicas, metodológicas y de actitud, con el objetivo de constituir que las IES construyan un diseño universal en el que todos sentir ciudadanos con los mismos derechos para expresarse y tener acceso a la construcción de conocimiento profesional y personal.

PALABRAS CLAVE

Enseñanza superior. Tecnología de asistencia. Sujeto sordo. Regulación. 


\section{Reflexões Iniciais}

A pesquisa, que ora apresentamos, é um estudo bibliográfico, que explicita o estado da arte em relação ao escopo que procura responder questões inerentes à acessibilidade do sujeito surdo e às Tecnologias Assistivas (TAs) no Ensino Superior, constituindo-se de conceitos científicos, observações e reflexões presentes na literatura.

$\mathrm{Na}$ busca por respostas a um problema enfrentado por um grupo social mais específico e, por conseguinte, pela sociedade como um todo, surge a necessidade de realização de estudos, cujo objeto é "descobrir respostas para problemas mediante o emprego de procedimentos científicos”. (GIL, 2008, p. 26). Assim, a pesquisa torna possível encontrar respostas e compreender os paradigmas emergentes, promovendo, também, mudanças a partir do seu resultado. Ao realizar uma pesquisa é necessário partir de um problema, buscar dados, teorias existentes e compreensões que já existam, referentes ao mesmo. É com este olhar que o Grupo de Pesquisa em Educação e Tecnologias, GPET, na linha de pesquisa que estuda a formação de professores e as tecnologias digitais.

Neste estudo, buscamos analisar como vem sendo regulamentada a acessibilidade do sujeito surdo através de tecnologia assistiva no Ensino Superior e quais dessas podem diminuir as barreiras comunicacionais entre ouvintes e surdos. Associados a este objetivo as reflexões estão alicerçadas aos principais encaminhamentos que as Instituições de Ensino Superior podem dar para garantir ao professor, um conjunto de saberes, tendo como foco os principais documentos que reportam à mesma e auxiliem na ação pedagógica quando o professor estiver na presença de um aluno surdo.

Ainda, necessitamos refletir sobre o campo teórico que vem sendo discutido no que tange à inclusão dos sujeitos surdos no Ensino Superior e como as Instituições de Ensino Superior - IES podem diminuir as barreiras comunicacionais entre os sujeitos ouvintes com os sujeitos surdos.

Quando se pensa em educar na sociedade atual, não se espera que o estudante seja um reprodutor das informações que obteve, mas sim que desenvolva suas capacidades para pesquisar, buscar informações, tornando-se um sujeito crítico que consiga opinar e intervir no seu meio. É oportuno, também, refletir que educar na contemporaneidade envolve a utilização de diferentes recursos facilitadores da aprendizagem, entre eles os tecnológicos. Nesse contexto, reconhece-se que o uso das tecnologias se tornou um importante meio de inclusão e interação no mundo, sendo algo cada vez mais presente na cultura. 


\title{
Aprofundando Saberes Sobre as Tecnologias Assistivas
}

Ao abordar a temática sobre educação de surdos, surge um conjunto de ideias e conceitos formais e informais com relação à mesma. A educação não se limita apenas a uma ciência com conceitos comprovados cientificamente. Abrange, também, o senso comum, valorizando o que há de experiências e vivências dos sujeitos que estão presentes na sociedade.

Quando a educação tem o objetivo de educar sujeitos, essa não se restringe apenas à transmissão dos conteúdos, teorias ou informações comprovadas cientificamente. A concepção de educação que está sendo tratada é aquela que auxilia os sujeitos a transformarem suas vidas em constante processo de aprendizagem. O que tanto se almeja é que a educação contribua para uma melhor formação pessoal e profissional dos sujeitos, auxiliando os mesmos na formação de suas identidades. Nesta perspectiva, a educação contribui para a formação do sujeito, de modo que este consiga aprimorar suas habilidades de comunicar-se, de compreender suas emoções e de constituir-se sujeito.

Moran (2012) nos provoca a pensar que educar é contribuir para que os professores e alunos consigam transformar suas vidas em um processo constante de aprendizagem nas organizações. Ao auxiliar os alunos neste processo de aprendizagem, é importante, também, contribuir à construção da identidade dos mesmos, sendo necessário desenvolver as habilidades de comunicação, compreensão e emoção, as quais lhe permitam ter seu espaço pessoal, social e profissional na sociedade.

\begin{abstract}
Na sociedade do Século 21, em razão da revolução tecnológica e epistemológica ocorrida ao longo das últimas três décadas, ocorrem mudanças vertiginosas no conhecimento científico e nos produtos do pensamento, cultura e arte. Tão intensa é a produção do conhecimento e sua divulgação, que ensinar para produzir não mais atende as demandas postas pela sociedade informacional e global em que estamos inseridos, a qual prioriza o domínio de certos saberes, habilidades e competências dos quais nós como educadores precisamos estar cientes e convencidos de sua necessidade. (NOGARO; CERUTTI, 2016, p. 40).
\end{abstract}

O termo tecnologia, originado na Grécia Antiga, significa conhecimento científico (teoria), transformado em técnica (habilidade). Dito de um modo mais explícito, "a tecnologia envolve um conjunto organizado e sistematizado de diferentes conhecimentos, científicos empíricos e até intuitivos, voltados para um processo de aplicação na produção e na comercialização de bens e serviços." (GRINSPUN, 1999, p. 49). A tecnologia é um suporte para o ser humano, ajudando o mesmo a realizar suas tarefas com maior facilidade.

As tecnologias estão presentes em nosso cotidiano em diversos espaços, seja no ambiente de trabalho, escolas, ambientes comerciais ou domiciliares e o seu uso tem se tornado cada vez mais natural que, muitas vezes, acaba sendo uma atitude involuntária. Isso porque as tecnologias foram incorporadas à vida, não sendo mais possível dissociá-las.

As redes sociais ou os aplicativos para aparelhos celulares são exemplos de tecnologias que facilitam a interação e a comunicação entre as pessoas, independentemente de estarem 
próximas ou distantes. Essa afirmação é, ainda, mais evidente quando se refere ao uso das Tecnologias da Informação e Comunicação (TICs), por pessoas com deficiência. Lévy (1999) destaca que a inserção das TICs na cultura e vida diária dos sujeitos é identificada pelo termo cibercultura, o qual está inserido no ciberespaço, conceito apresentado pela seguinte definição:

Eu defino o ciberespaço como o espaço de comunicação aberto pela interconexão mundial dos computadores e das memórias dos computadores. Essa definição inclui o conjunto dos sistemas de comunicação eletrônicos (ai incluídos os conjuntos de redes hertzianas e telefônicas clássicas), na medida em que transmitem informações provenientes de fontes digitais ou destinadas a digitalização. Insisto na codificação digital, pois ela condiciona o caráter plástico, fluido, calculável com precisão e tratável em tempo real, hipertextual, interativo e, resumindo, virtual da informação que é, parece-me, a marca distinta do ciberespaço. (LÉVY, 1999, p. 93).

Nesse contexto, a cibercultura amplia a comunicação, rompendo as barreiras comunicacionais entre os sujeitos. Desse modo, possibilita experimentar, coletivamente, diferentes formas de comunicação, as quais vão além das que as mídias clássicas propõem.

Quando são agregadas tecnologias para auxiliar na comunicação, está se buscando aperfeiçoar a eficiência da atividade humana em todas as esferas, principalmente, na produtiva. A tecnologia, também, caracteriza-se pela transformação no campo tecnológico, portanto, consequentemente no mercado de bens, serviços e consumo no modo de produção, na educação/qualificação e nas relações sociais.

Vivemos na era da informação com o desafio de que cada sujeito interaja em seus espaços sociais, reaprendendo a integrar o humano com o tecnológico, buscando, assim, as informações e maneiras diferenciadas de utilizá-las no seu cotidiano, seja para uso pessoal ou profissional.

$\mathrm{Na}$ concepção de Pinto (2004), quando se integram as tecnologias temáticas, audiovisuais, orais, musicais, textuais, corporais e lúdicas numa visão inovadora, é possível adquirir resultados positivos no que tange à aprendizagem. Não basta apenas ter conhecimento da existência da tecnologia, é necessário buscar maneiras para compreender de que forma ela pode auxiliar e qual sua função.

Nesse sentido, ocorrem várias renovações nos meios tecnológicos em diferentes áreas e, consequentemente, a sociedade está em constantes transformações, exigindo que as pessoas inseridas nela busquem um aperfeiçoamento. $\mathrm{O}$ acesso às TICs desencadeia transformações sociais e diversas mudanças na forma de construir o conhecimento, sendo assim, a sociedade e os locais não podem desconsiderar tais movimentos.

Para Valente (2010), se o sujeito que está fazendo uso de determinadas tecnologias não compreender a sua função ou características, a mesma não será assimilável. Portanto, as mesmas estão sendo aprimoradas para se acomodar aos conhecimentos e necessidades de seus usuários, utilizando linguagens de interfaces sensoriais, sonoras e gestuais no seu desenvolvimento para facilitar esta apropriação digital. 
Diante das mudanças provocadas pelo desenvolvimento tecnológico, é importante salientar que os usos desses recursos precisam acrescentar um significado aos usuários, que devem se apropriar criticamente dessas tecnologias, de modo a descobrir as possibilidades que as mesmas oferecem.

Fica evidente que as tecnologias não devem ser vistas como algo que substitua o ser humano, mas sim como dispositivos que venham facilitar e complementar a capacidade da pessoa que as utiliza, aprimorando, nesse sentido, a atividade humana. Por isso, é importante que os sujeitos tenham consciência de que as tecnologias necessitam de um usuário para gerar uma ação.

Além das tecnologias utilizadas como ferramentas de suporte humano nas atividades do cotidiano, há, também, as tecnologias digitais, as quais podem facilitar a comunicação entre os sujeitos e serem utilizadas para ampliar o conhecimento intelectual dos seus usuários.

Ao se compreender a tecnologia como suporte para o ser humano, entende-se que esta, quando aplicadas ou postas em movimento, podem auxiliar e minimizar as limitações dos sujeitos. As tecnologias, nesse sentido, representam possibilidades de auxílio para as pessoas com deficiência auditiva ou surdas, especialmente por facilitar a comunicação não-verbal com os sujeitos ouvintes e com o mundo.

Nesse contexto, a inclusão das pessoas com deficiência ganhou novas dimensões com o avanço de recursos físicos e tecnológicos. Utilizam-se, no cotidiano, diversas ferramentas com o intuito de facilitar e favorecer as tarefas realizadas, como canetas, telefones celulares, talheres, automóveis, entre outros recursos que estão presentes nas rotinas diárias e que facilitam a realização das atividades.

Para uma pessoa com deficiência, a tecnologia se apresenta não só para facilitar, mas para tornar possível a realização de uma ação necessária ou desejada. Por meio da tecnologia, uma pessoa com deficiência tem possibilidades de mobilidade, controle de ambiente, acesso ao computador, comunicação, realização de tarefas do cotidiano, entre outras atividades. (WAGNER; LAZZERI; RAMOS, 2014, p. 80).

Pensando na inclusão dos surdos, é fundamental analisar na promoção da acessibilidade destes sujeitos às tecnologias, por acreditar que existem recursos tecnológicos e didáticos que facilitam a comunicação entre surdos e o mundo. Dito de outro modo, as tecnologias devem ser vistas como parte de uma solução e não o contrário.

Desse modo, é necessário que os ambientes sociais estejam adequados e aptos para atender pessoas com qualquer tipo de deficiência, ampliando as chances de que esse perfil da população tenha experiências satisfatórias a partir de suas vivências. É possível utilizar recursos ou tecnologias digitais que possam auxiliar nesse processo de inclusão.

O Decreto Federal no 3.298/99 (BRASIL, 1999) cita as ajudas técnicas (AT), as quais são definidas no seu Art. 19, como]

\begin{tabular}{l|l|l|l|l|l} 
C Rev. Inter. Educ. Sup. & Campinas, SP & v.6 & $1-17$ & $\mathrm{e} 020040$ & 2020 \\
\hline
\end{tabular}


Os elementos que permitem compensar uma ou mais limitações funcionais motoras, sensoriais ou mentais da pessoa portadora de deficiência, com o objetivo de permitirlhe superar as barreiras da comunicação e da mobilidade e de possibilitar sua plena inclusão social.

No parágrafo único deste artigo encontramos a lista de ajudas técnicas, as quais são itens de direito:

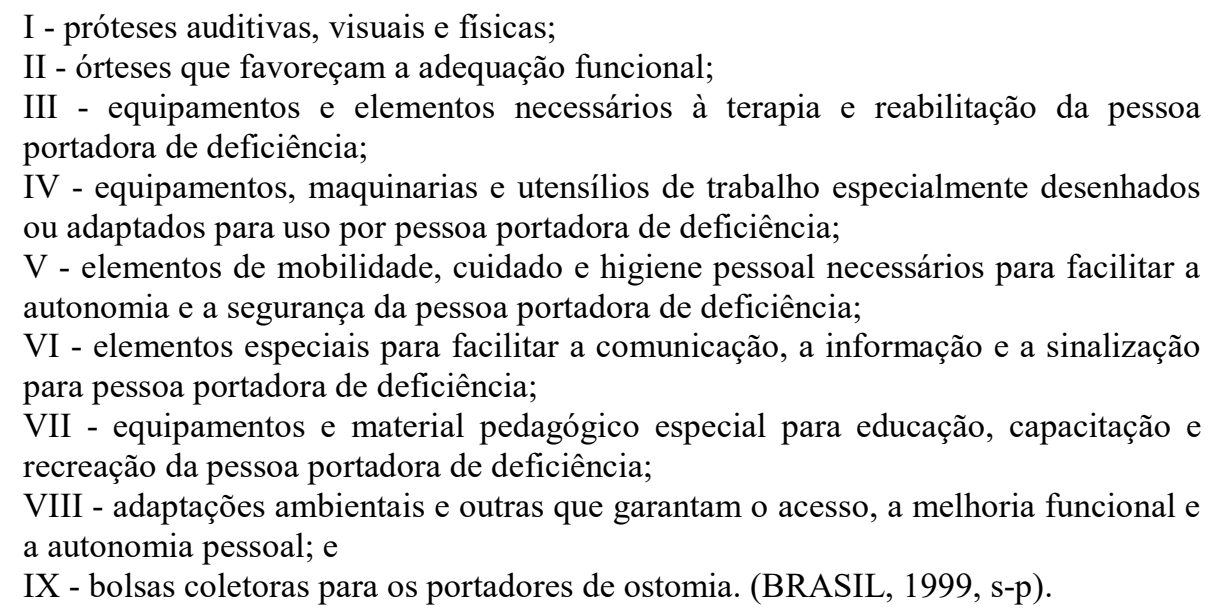

Vale ressaltar que a terminologia "Ajudas Técnicas", encontrada na legislação brasileira, refere-se, atualmente, à denominação de Tecnologia Assistiva (TA), a qual deve colaborar para a inclusão social de pessoas com deficiências, sejam elas visual, auditiva, física e/ou intelectual, reduzindo, assim, as limitações decorrentes das mesmas. Já o termo Tecnologia Assistiva é "utilizado para identificar todo o arsenal de recursos e serviços que contribuem para proporcionar ou ampliar habilidades funcionais de pessoas com deficiência, e consequentemente, promover vida independente e inclusão." (WAGNER; LAZZERI; RAMOS, 2014, p. 80).

Entre as TAs, encontramos as TICs, que podem ser utilizadas de diferentes maneiras e classificadas de diversas formas, de acordo com os objetivos do pesquisador, sendo que cada uma tem por objetivo saciar ou aprimorar algo. Servem de suporte principalmente, para as pessoas com alguma limitação ou deficiência, em diferentes atividades, seja das mais simples, até as mais complexas.

Para Santarosa (1997), as TICs podem ser classificadas em quatro áreas: como sistemas auxiliares ou prótese para a comunicação; utilizadas para controle do ambiente; como ferramentas ou ambientes de aprendizagem e; como meio de inserção no mundo do trabalho profissional. Optamos, neste estudo, por descrever as TICs como facilitadoras da comunicação e consequente, da aprendizagem do sujeito surdo, como explica Santarosa

As TIC como sistemas auxiliares ou prótese para a comunicação: talvez esta seja a área onde as TIC tenham possibilitado avanços mais significativos. Em muitos casos o uso dessas tecnologias tem se constituído na única maneira pela qual diversas pessoas podem comunicar-se com o mundo exterior, podendo explicitar seus desejos e pensamentos. Essas tecnologias têm possibilitado a otimização na utilização de Sistemas Alternativos e Aumentativos de Comunicação (SAAC), com a informatização dos métodos tradicionais de comunicação alternativa, como os sistemas Bliss, PCS ou PIC, entre outros. [...].

\begin{tabular}{l|l|l|l|l|l} 
(C) Rev. Inter. Educ. Sup. & Campinas, SP & v.6 & $1-17$ & e020040 & 2020
\end{tabular}


As tic como ferramentas ou ambientes de aprendizagem: as dificuldades de muitas pessoas com necessidades educacionais especiais no seu processo de desenvolvimento e aprendizagem têm encontrado uma ajuda eficaz na utilização das tic como ferramenta ou ambiente de aprendizagem (SANTAROSA, 1997, p. $115)$.

Utilizando as TICs com o intuito da comunicação, é possível romper com algumas barreiras comunicacionais. Indiferente dos sujeitos possuírem ou não limitações relacionadas à comunicação, elas permitem estabelecer contato com outros sujeitos, estando eles próximos ou não. Pode, também, haver uma comunicação entre sujeitos que utilizam diferentes maneiras para se comunicar.

Partindo dessa ideia, as TICs enquanto ambientes de aprendizagem, quando utilizadas juntas, podem auxiliar na aprendizagem do sujeito surdo, auxiliando o sujeito que consiga estabelecer comunicação com outros sujeitos e, também, facilitando a sua aprendizagem através de recursos digitais.

Ampliando as TICs, têm-se as Tecnologias Digitais da Informação e Comunicação (TDICs), que, a partir de diferentes bases tecnológicas e equipamentos, possibilitam a associação de diversos indivíduos e ambientes numa rede, na qual é possível a comunicação entre os mesmos, ampliando os recursos tecnológicos que já são utilizados. Além de ferramentas tecnológicas, as TDICs podem ser vistas como ferramentas cognitivas, sendo possível expandir o conhecimento intelectual dos usuários. Para isso, basta que os mesmos saibam utilizá-las, aprimorando as tecnologias digitais, possibilitando a criação de novas formas de comunicação e expressão, entre essas, criação de imagens, sons, animações e combinações dessas modalidades, amparados nas reflexões de Valente (2007).

Atualmente, é possível o contato com diferentes tecnologias, as quais, na maioria das vezes, são de fácil acesso para a população. No entanto, para que as tecnologias possam auxiliar no processo de inclusão, é necessário o interesse das pessoas em buscar o aperfeiçoamento para aprender a manuseá-las de forma correta. Os usuários precisam ter autodisciplina, criatividade, capacidade de trabalhar em grupo, serem adaptáveis e flexíveis, além de constantemente buscarem novas informações para aprimorarem o conhecimento, saberem tomar decisões, serem críticos e não se deixarem acomodar, como ressalta Betts:

Além de transformar-se num aprendiz vitalício e ser responsável pela própria carreira, o trabalhador, para ter sucesso na era do conhecimento, terá de desenvolver outras competências. Para citar apenas três, a primeira é aprender a aprender, gostar de aprender, ter curiosidade, capacidade de coletar, organizar, estruturar, analisar e qualificar a informação e construir conhecimento - ser autodidata. A segunda é uma certa inconformidade com o estado presente, uma disposição para o novo, para mudar constantemente, enfim, altamente adaptável. A terceira é a autodisciplina, ou seja, a clareza de objetivos, gestão do tempo, sem as quais terá uma 'indigestão' informacional dado o volume de informações espalhadas e acessíveis mundo afora (BETTS, 2005, p. 28-29). 
Ao pensar no fácil acesso às mídias digitais e nos avanços tecnológicos, é fundamental a inclusão destes nos ambientes em que ocorre a difusão do conhecimento ou em que surge a necessidade de saciar algo mesmo que, em alguns locais, a utilização destas ferramentas esteja em fase de avaliação ou vistas como polêmicas. (PERNISA JUNIOR; VIANA, 2010).

As tecnologias beneficiam, em geral, um público de massa, porém, é notável que desempenham um papel fundamental com deficientes, uma vez que permitem desenvolver atividades antes inacessíveis devido às suas limitações. Há muitas tecnologias são pensadas e criadas para suprir limitações específicas de cada deficiência, tendo em vista que, com o aprofundamento do conhecimento, muitas perguntas surgirão e, assim, poderão mostrar novas opções de tecnologias.

Ao pensar nas tecnologias voltadas para a independência dos seres humanos, é possível mencionar a Tecnologia Assistiva (TA), utilizada com o objetivo de mediação, ferramenta e instrumento que facilite as atividades que envolvam a autonomia, principalmente das pessoas com deficiências (GALVÃO FILHO, 2009).

É possível compreender as TAs como recursos que permitem a ampliação das habilidades ou, então, como suporte para as limitações de cada sujeito com deficiência, podendo essas serem adaptadas para diferentes áreas e com diferentes objetivos. Em um mundo com aceleradas e constantes mudanças, a TA ocupa uma área do conhecimento e de pesquisa de grande relevância para a real inclusão social de pessoas com deficiência.

Passados pouco mais de um quarto de século, de criação da URI (sua Portaria de Reconhecimento data de 19 de maio de 1992), esse cenário assume novas perspectivas e, hoje, a internacionalização é uma realidade que vai se impondo, se consolidando e trazendo novos desafios e necessidades. Vale destacar que os intensos debates sobre a temática têm provocado um amadurecimento do processo, permitindo que o entendimento sobre o que seja internacionalização, passe de uma visão, inicialmente, mais restrita a ideia de intercâmbio de acadêmicos e professores, para acrescentar a ela a construção de convênios, eventos, acordos e termos tenham seus nascedouros a partir dos desejos e necessidades de professores ou acadêmicos, referendados pelos Reitores, para se tornarem ações efetivas que nascem no bojo dos grupos de pesquisa, das relações profissionais e pessoais entre colegas, que comungam de temáticas de pesquisa e interesses de estudos comuns.

\section{As Tecnologias Assistivas no Ensino Superior}

Ao pensar nas tecnologias assistivas no Ensino Superior é necessário encontrar estratégias que rompam as barreiras de comunicação entre surdos e ouvintes. Para isso, as tecnologias assistivas são alternativas para minimizar tais distanciamentos. Nogaro e Cerutti (2016), ressaltam que os dispositivos comunicacionais atuais oportunizam possibilidades de interações entre as pessoas, sendo que as técnicas disponíveis revolucionaram a maneira de interação e comunicação entre os acadêmicos presentes nas universidades. Os autores ressaltam, ainda: 
As novas tecnologias estão cada vez mais presentes, abrindo amplas oportunidades de produção individual e coletiva, gerando a construção de conhecimentos a partir das interações com o meio, pois a aprendizagem vai sendo construída pelas interações, cooperações, acessos e trocas de informações que sempre fizeram parte das vivências da sociedade, mas que nem sempre foram partilhadas pela ausência de ferramental adequado. (NOGARO; AUTOR, 2016, p. 94).

A tecnologia assistiva está inserida e é utilizada pelos usuários, seja para realização de atividades mais simples e corriqueiras até as mais complexas, tais como, locomover-se, estabelecer comunicação com outros sujeitos, melhorar a visão, entre outras. Quando há uma relação com produções coletivas, os sujeitos estabelecem vínculos e interações, facilitando a comunicação entre sujeitos surdos e ouvintes não somente nas IES, mas também em outros ambientes e situações.

O Art. 43, da Lei Diretrizes e Bases da Educação Nacional - LDB, nº 9.394/96, prevê que as IES têm como finalidade "estimular a criação cultural e o espírito científico e do pensamento reflexivo; [...] incentivar o trabalho de pesquisa e investigação científica, [...], e desse modo, desenvolver o entendimento sobre o homem e o meio em que vive; [...]." (MOROSINI, 2006, p. 59). Sendo assim, a educação de Ensino Superior é o locus para desencadear, nos acadêmicos, o desejo de aperfeiçoamento profissional e cultural e, por meio deste, estimular a reflexão sobre as situações cotidianas, principalmente de natureza regional e nacional, prestando respostas e serviços especializados à comunidade, para assim estabelecer uma relação de reciprocidade. (MOROSINI, 2006).

Aliada à inclusão do sujeito surdo neste segmento de ensino, surge a necessidade das IES desenvolverem e pesquisarem alternativas que possam facilitar e auxiliar os mesmos para que não se sintam prejudicados no âmbito do conhecimento intelectual e crescimento pessoalprofissional. Esta preocupação é justificada ao levar-se em consideração que no contexto das IES, há prevalência das características próprias da comunidade ouvinte e a língua Portuguesa é a oficial, sendo as demais 180 línguas reconhecidas no Brasil. No uso do Português oral/auditivo o sujeito surdo tornar-se minoria perante os sujeitos ouvintes, como explica Valetini:

Pessoas que pertencem a minorias geralmente enfrentam desafios cotidianos para interagir com os demais. Uma das barreiras mais difícil de ser rompida é a do preconceito. É comum o 'pré' 'conceito' de que o surdo também tem dificuldades cognitivas. Uma pessoa surda pode ou não ter dificuldades cognitivas, mas isso deverá ser avaliado adequadamente para não confundir o que pode ser uma dificuldade de compreensão em função da língua, ou uma dificuldade de compreensão em nível cognitivo. (VALENTINI, 2012, p. 24).

Devido às limitações auditivas, o sujeito surdo, muitas vezes, acaba se privando de informações e contatos no cotidiano, da mesma maneira em que um público com desconhecimento da Língua de Sinais acaba gerando uma privação aos sujeitos surdos quanto às suas necessidades, o que torna essencial a presença de um tradutor e intérprete. 
A Lei ${ }^{\circ}$ 12.319/10 (BRASIL, 2010), regulamenta a profissão de Tradutor e Intérprete da Língua de Sinais (TILS), este profissional é habilitado para realizar traduções entre LIBRAS-Português ou vice-versa, sendo primordial a sua presença na IES para que o sujeito surdo não seja privado das informações ou excluído em seu grupo acadêmico.

Ressaltamos que somente a presença do intérprete no ambiente onde o sujeito surdo está inserido não é garantia de uma plena inclusão. Para Stumpf (2008, p. 27):

[...] a inclusão acontece a partir de dois movimentos: da construção social de toda a sociedade que entende e acolhe, e dos surdos, que vão participar porque se sentem acolhidos [...]. Este movimento da sociedade implica em responsabilidade social como prática constante no agir das pessoas e das instituições a partir de uma posição ética, uma posição em que a liberdade individual é posta em segundo plano a fim de que a justiça assuma primazia nas relações intersubjetivas.

Percebemos que a inclusão do sujeito surdo se torna mais viável quando há planejamento, quando os assuntos são pensados considerando a preservação da identidade surda e, partindo das características próprias da mesma, para assim elaborar alternativas que visem a inclusão desses sujeitos.

A LIBRAS é o alicerce da compreensão e comunicação dos surdos, portanto, quando os ambientes e os profissionais estão habilitados quanto à mesma, contribuem para uma inclusão com qualidade destes sujeitos. Porém, ao pensar na inclusão do sujeito surdo no Ensino Superior, é importante considerar que a presença do intérprete não é suficiente, tornando necessário que a equipe de profissionais de atendimento especializado busque, de maneira coletiva, alternativas e metodologias apropriadas, também, para os estudantes surdos. É fundamental um conjunto de ações para que este aluno se sinta integrado no espaço educacional, criando vínculos afetivos, profissionais e pessoais com o restante da comunidade escolar.

É necessário refletir sobre a inclusão dos sujeitos surdos no Ensino Superior e quais são as Tecnologias Assistivas (TA) presentes na contemporaneidade que possam diminuir as barreiras comunicacionais. Também registramos a definição do Comitê de Ajudas Técnicas (CAT), expedida pela Secretaria Especial dos Direitos Humanos (SEDH) da Presidência da República, define-se (TA) como sendo:

[...] uma área do conhecimento, de característica interdisciplinar, que engloba produtos, recursos, metodologias, estratégias, práticas e serviços que objetivam promover a funcionalidade, relacionada à atividade e participação, de pessoas com deficiência, incapacidades ou mobilidade reduzida, visando sua autonomia, independência, qualidade de vida e inclusão social. (BRASIL, 2009, p. 9).

É possível perceber que o assunto em questão ainda está em fase inicial de discussão no cenário acadêmico no Brasil. Em pesquisa realizada na Biblioteca Digital Brasileira de Teses e Dissertações (BDTD) do Instituto Brasileiro de Informação em Ciência e Tecnologia (IBICT, 2017), entre os anos de 2006 a $2016^{1}$, buscamos oito descritores, para o escopo do estudo:

${ }^{1}$ Pesquisa realizada em 28 de abril de 2017. 
- tecnologias,

- tecnologia assistivas,

- deficientes,

- surdos,

- Instituições de Ensino Superior,

- inclusão de surdos no Ensino Superior,

- acessibilidade para os surdos nas Instituições de Ensino Superior e,

- tecnologia assistiva e acessibidade para os surdos nas instituições de Ensino Superior.

A partir desses, coletamos 36.644 trabalhos, sendo 27.347 dissertações e 9.297 teses. A análise permitiu constatar que a maior parte dos trabalhos encontrados $(75 \%)$ com relação ao tema são dissertações, havendo uma grande diferença no percentual em relação às teses, que representam $25 \%$ do total. Para que o tema fosse filtrado, pesquisamos os descritores de maneira separada, entre dissertações e teses. Cabe destacar que futuras pesquisas serão importantes, com a utilização de um protocolo de inclusão e exclusão de texto, bem como, a redefinição de argumentos de pesquisa.

Com relação ao descritor "tecnologias", encontramos um total de 31.023, sendo que $75 \%$ correspondem às dissertações e $25 \%$ às teses realizadas sobre a temática. Por ser um tema amplo, houve uma delimitação, passando-se a considerar os trabalhos realizados com o descritor "Tecnologia Assistiva". Encontramos, então, 246 trabalhos, em que 189 (77\%) correspondem à dissertações e 57 (23\%) correspondem à teses.

Devido ao interesse em pesquisar as tecnologias atreladas ao tema inclusão de surdos e tendo ciência que variados níveis de baixa audição estão dentro da categoria deficiência auditiva, pesquisamos, também, trabalhos com o descritor "deficientes". Neste, 2.224 trabalhos, dos quais 1557 (70\%) são classificados como dissertações e 667 (30\%) como teses.

Partindo do descritor "surdos", localizamos 779 trabalhos, destes 608 (78\%) correspondem à dissertações e $171(22 \%)$ à teses.

Tendo em vista a inclusão de alunos com diferentes deficiências em escolas regulares no Brasil, são intensificadas e regulamentadas legislações que dão suporte não só para inserir estes alunos, mas também, orientar como deve ser feita essa inclusão. Sabendo que os sujeitos surdos então ingressando nas Instituições de Ensino Superior (IES), o descritor "Instituições de Ensino Superior", 2.341 trabalhos, sendo que 1662 (71\%) corresponde à dissertações e 679 $(29 \%)$ à teses.

Com base nesses dados, através do descritor "Inclusão de surdos no Ensino Superior", foi encontrado um total de 29 trabalhos, 24 (83\%) classificam-se como dissertações e cinco (17\%) como teses. Vale ressaltar que um dos trabalhos encontrados, também está incluído no próximo descritor, "Acessibilidade para os surdos nas instituições de Ensino Superior." 
No que tange a comunidade surda, há resoluções, leis e documentos, específicos para a inclusão, demonstrando, sempre, a necessidade comunicacional da Língua Brasileira de Sinais (LIBRAS). Assim, a pesquisa seguiu observando a maneira como está sendo trabalhada a acessibilidade para sujeitos surdos, o que foi pesquisando através do descritor "Acessibilidade para os surdos nas instituições de Ensino Superior." Encontramos apenas dois trabalhos, tendo um percentual de $50 \%$ para dissertações e $50 \%$ para teses. Ainda, incipiente, o estudo aponta a necessidade de avanços para que outros sujeitos surdos encontrem esta possibilidade. Há, ainda, a preparação das IES em desenhar políticas de acolhimento e desenvolvimento de ações junto a este grupo social.

Visando as tecnologias assistivas como facilitadoras na acessibilidade para surdos nas instituições de Ensino Superior, a busca se deu através do descritor "Tecnologia Assistiva e acessibilidade para os surdos nas instituições de Ensino Superior”, porém, não foi encontrado nenhum trabalho referente ao assunto.

Em razão de não ter sido encontrado nenhum trabalho com o descritor "Tecnologia assistiva" e "Acessibilidade para os surdos nas instituições de Ensino Superior" e devido o descritor "Inclusão de surdos no Ensino Superior" e o descritor "Acessibilidade para surdos nas instituições de Ensino Superior" estar mais próximo do tema, analisamos os mesmos por regiões geográficas. A busca resultou em 31 trabalhos científicos, sendo que um mesmo trabalho encontra-se em dois descritores.

Partindo do descritor "Inclusão de surdos no Ensino Superior", fica explícito que 38\% dos trabalhos foram desenvolvidos em universidades da Região Sul do Brasil, seguido de $27 \%$ da Região Sudeste, $14 \%$ da Região Centro-Oeste e $21 \%$ na Região Nordeste, sendo que a Região Norte não apresenta nenhum trabalho.

Com relação ao descritor "Acessibilidade para os surdos nas instituições de Ensino Superior" que 33\% dos trabalhos foram desenvolvidos em universidades da Região Nordeste do Brasil, seguido de 33\% da Região Sudeste, 33\% da Região Sul e nenhum na Região Norte.

Como já mencionado, quando a temática está atrelada ao sujeito surdo no Ensino Superior, com o foco na acessibilidade, o estudo nos aponta que há um vasto caminho a ser percorrido, principalmente em algumas regiões de nosso país. O fato de não termos um universo de trabalhos pesquisados nos distancia de um horizonte de operações institucionalizadas nas IES.

\section{Conclusão}

Refletindo sobre a inclusão dos sujeitos surdos, historicamente há registros de barreiras comunicacionais devido à predominância da língua oral na sociedade. Com o advento das tecnologias, os sujeitos surdos passaram a ter novas oportunidades de comunicação com outros sujeitos ouvintes. Partindo desse pressuposto, é possível verificar que por meio das tecnologias é possível tornar as atividades mais acessíveis e romper parte das barreiras na comunicação dos sujeitos surdos com os ouvintes. 
Em meio a pesquisa, concluímos que existe um vasto acervo de trabalhos com relação aos descritores "tecnologias" e "deficientes", porém, há poucos resultados voltados às pesquisas em que exista uma relação entre tecnologias e surdos no Ensino Superior.

A partir do estado do conhecimento realizado, foi pesquisado o que vem sendo realizado sobre os descritores "Tecnologias", "Tecnologia Assistiva", "Deficientes", "Surdos", "Instituições de Ensino Superior", "Inclusão de surdos no Ensino Superior", "Acessibilidade para os surdos nas instituições de Ensino Superior" e "Tecnologia Assistiva e acessibilidade para os surdos nas instituições de Ensino Superior”.

Foi possível verificar, também, pesquisas em que as Tecnologias Assistivas são facilitadoras para a acessibilidade de surdos no Ensino Superior e, ainda, não foram contempladas, o que chama atenção para a necessidade de realização de futuros estudos acerca da temática para esse segmento de ensino.

Partindo do pressuposto de não existirem trabalhos relacionados ao descritor "Tecnologia Assistiva e acessibilidade para os surdos nas instituições de Ensino Superior" e visando o direito dos mesmos, aliado à importância de toda a sociedade em reconhecê-los como sujeitos de subjetividades e cultura própria, torna-se essencial a realização de novos estudos à área.

Diante do exposto, fica evidente a relevância da temática da inclusão de sujeitos surdos. Deste modo, as discussões com embates teóricos e os amparos legais intensificam-se, o que contribuiu para o respeito e reconhecimento do sujeito surdo. É compreensível, então, que os sujeitos envolvidos também alterem a maneira de pensar em suas atitudes no cotidiano. A IES, com seu capital intelectual possuem o desafio de interpretar a fundo a legislação e operála de maneira a realizar a inclusão e a criar mecanismos que potencializem o acesso e a permanência do sujeito surdo.

Considerando que os avanços são relevantes para compreender a educação e a cultura surda, é imprescindível versar-se sobre a identidade desses sujeitos. Assim, torna-se oportuno refletir, também, sobre o contexto histórico e as questões que envolvem a formação da identidade dos mesmos.

Neste contexto, a inclusão de alunos com diferentes deficiências em Instituições de Ensino Superior (IES) no Brasil intensifica-se e regulamenta-se a partir e por meio de políticas públicas, as quais dão suporte não somente de quem inserir, mas também regimenta como deve ser feita esta inclusão. No que tange à comunidade surda, há Resoluções, Leis e Documentos específicos, demonstrando sempre a necessidade comunicacional da Língua Brasileira de Sinais (LIBRAS).

Notamos, também, o avanço das TA as quais cada vez mais estão sendo aprimoradas para que facilitem e resultem em ações positivas para seus usuários. Sabendo que a mesma pode reduzir as limitações das pessoas com deficiências, é importante refletir o quanto a cibercultura vem sendo um elemento desencadeador de produção de TA para os alunos surdos nas IES.

\begin{tabular}{l|l|l|l|l|l} 
(C) Rev. Inter. Educ. Sup. & Campinas, SP & v.6 & $1-17$ & $\mathrm{e} 020040$ & 2020 \\
\hline
\end{tabular}


É imprescindível que locais educativos, principalmente nas IES, sejam adequados para receber pessoas com alguma deficiência, sejam os profissionais que atuam nestas instituições ou os alunos que por um determinado período de suas vidas estarão vivendo a sua formação. Sabemos que estas pessoas possuem os mesmos direitos e, também, necessitam, muitas vezes, de locais físicos adequados ou de apoio para se comunicar. Políticas nas IES para atender tais demandas, apresentam-se cada vez mais relevantes.

Considerando a premência de inclusão dos surdos e o avanço tecnológico, é oportuno pesquisar, através de TA, o que os documentos regulatórios abordam sobre a inclusão de estudantes surdos nas IES. Para tanto, é necessário verificar quais são os amparos nos materiais teóricos e metodológicos que possam facilitar e se é possível embasar a acessibilidade necessária, para que os alunos surdos se sintam realmente incluídos e não apenas integrados, representando somente um dado quantitativo nas matrículas.

Atualmente, é possível perceber, nas ações cotidianas, que os sujeitos surdos usufruem das tecnologias diariamente, principalmente as que se caracterizam como tecnologias da comunicação, em que expressam suas críticas, ideias, sugestões, opiniões sobre assuntos diversos, relatam acontecimentos, entre outros. As tecnologias se tornaram uma alternativa primordial para os sujeitos surdos estabelecerem comunicação com outros sujeitos.

Partindo do pressuposto que através dessas tecnologias, os surdos expressam-se na maioria das vezes, por meio da Língua Portuguesa escrita, presume-se que todas as pessoas vinculadas a essas tecnologias possuem acesso às ideias dos surdos, até mesmo as que desconhecem a LIBRAS, reconhecida pela Lei 10.436/2002. (BRASIL, 2010).

Ainda, concluímos que estudar a educação da pessoa surda nos reporta não só a questões referentes aos seus limites e possibilidades, como também aos preconceitos existentes nas atitudes da família, sociedade e, também, nas IES, visto que enfrentam inúmeros entraves para participar da Educação Superior, decorrentes da perda de audição e da forma como se estruturam as propostas educacionais. É destaque, realizar novos estudos correlatos, capazes de analisar como vem sendo regulamentada a acessibilidade do sujeito surdo através de Tecnologia Assistiva no Ensino Superior e quais dessas podem diminuir as barreiras comunicacionais entre ouvintes e surdos.

\section{Referências}

ADORNO, Theodor Wiesengrund. Educação e emancipação. 2. ed. São Paulo: Paz e Terra, 2000 .

BETTS, D. N. Desafios para o docente do século XXI: o impacto das novas tecnologias de informação e comunicação. In: DANILUK, Ocsana Sônia. (Org).; QUEVEDO, Hercília Fraga de.; MATTOS, Mára Beatriz Pucci de. (Org.). Conhecimento sem fronteira. 1. ed. Passo Fundo: UPF Editora, 2005.

BRASIL. Decreto Federal no 3.298, de 20 de dezembro de 1999. Regulamenta a Lei ${ }^{\circ}$

\begin{tabular}{l|l|l|l|l|l} 
(C) Rev. Inter. Educ. Sup. & Campinas, SP & v.6 & $1-17$ & e020040 & 2020 \\
\hline
\end{tabular}


7.853, de 24 de outubro de 1989, dispõe sobre a Política Nacional para a Integração da Pessoa Portadora de Deficiência, consolida as normas de proteção, e dá outras providências. Brasília, 20 de dezembro de 1999. Disponível em:

https://www.planalto.gov.br/ccivil_03/decreto/D3298.htm. Acesso em: 28 jul. 2017.

BRASIL. Lei $\mathbf{n}^{\mathbf{0}} \mathbf{1 2 . 3 1 9}$, de $1^{\circ}$ de setembro de 2010. Regulamenta a profissão de Tradutor e Intérprete da Língua Brasileira de Sinais - LIBRAS. Brasília, DF. Disponível em: http://www.planalto.gov.br/ccivil_03/_Ato2007-2010/2010/Lei/L12319.htm. Acesso em: 25 jul. 2017.

GALVÃO FILHO, Teófilo Alves. Tecnologia Assistiva para uma escola inclusiva: apropriação, demandas e perspectivas. 2009. 346 f. Tese (Doutorado em Educação) Faculdade de Educação, UFBA, Salvador, 2009.

GIL, Antônio Carlos. Como elaborar projetos de pesquisa. 4. ed. São Paulo: Atlas, 2002.

GRINSPUN, Mirian Paura Sabrosa Zippin (Org). Educação tecnológica: desafios e perspectivas. São Paulo: 1999.

LÉVY, Pierre. Cibercultura. São Paulo: Editora 34, 1999.

MORAN, José Manuel. Novas tecnologias e mediação pedagógica. Campinas: Papirus, 2012.

MOROSINI, Marilia Costa. Enciclopédia de pedagogia universitária: glossário v. 2.

Brasília: Instituto Nacional de Estudos e Pesquisas Educacionais Anísio Teixeira, 2006.

NOGARO, Arnaldo. CERUTTI, Elisabete. As TICs nos labirintos da prática educativa. Curitiba: CRV, 2016.

PERNISA JUNIOR, Carlos. VIANA, Fernanda. Interfaces do Saber: o uso das tecnologias digitais na difusão do conhecimento. Impulso, Piracicaba, SP, v. 20, n. 49, jan./jun. 2010.

PINTO, Marcianinha Aparecida. As novas tecnologias e a educação. 2004. Disponível em: http://www.portalanpedsul.com.br/admin/uploads/2004/Poster/Poster/04_53_48_AS_NOVA S_TECNOLOGIAS_E_A_EDUCACAO.pdf. Acesso em: 08 jun. 2017.

SANTAROSA, Lucila Maria Costi. "Escola virtual” para a educação especial: ambientes de aprendizagem telemáticos cooperativos como alternativa de desenvolvimento. Revista de Informática Educativa, Bogotá, Colômbia, v. 10, n. 1, p. 115-138, 1997.

STUMPF, Marianne Rossi. Mudanças estruturais para uma inclusão ética. In: QUADROS, Ronice Muller de. Estudos Surdos III. Petrópolis, RJ: Arara Azul, 2008. p. 14-29.

VALENTE, José Armando. As tecnologias digitais e os diferentes letramentos. Pátio Revista Pedagógica, Porto Alegre, v. 11, p. 12-15, 2007.

VALENTE, José Armando. As tecnologias e a verdadeira inovação. Ensino Fundamental, Pátio Revista Pedagógica, Porto Alegre, v. 14, p. 6-9, 2010.

\begin{tabular}{|l|l|l|l|l|l|} 
(C) Rev. Inter. Educ. Sup. & Campinas, SP & v.6 & $1-17$ & e020040 & 2020 \\
\hline
\end{tabular}


VALENTINI, Carla Beatris. Inclusão no Ensino Superior: especificidades da prática docente com estudantes surdos. Caxias do Sul: Educar, 2012.

WAGNER, Geovane Cristina. LAZZERI, Cristiane. RAMOS, Fabiane dos Santos.

Tecnologia assistiva: uma ferramenta para inclusão escolar. In: SILUK, Ana Cláudia Pavão. (Org.). Atendimento Educacional Especializado: Processos de Aprendizagem na Universidade. 1. ed. 1. Reimpr. Santa Maria: Laboratório de pesquisa e documentação - CE. Universidade de Santa Maria: UFSM, 2014. 